\title{
Photo Elicitation and Photovoice: How Visual Research Enables Empowerment, Articulation and Dis-Articulation
}

\author{
Linda Hopkins \\ Postgraduate Research Student, Contextual Theology, Luther King House \\ Educational Trust, University of Manchester, Manchester, UK \\ revlindahopkins@gmail.com \\ Eleanor Wort \\ Tutor (Module Lead) Learning and Development Team, Church Army, \\ Sheffield, UK \\ eleanorcourse@gmail.com
}

\begin{abstract}
Photo elicitation and photovoice are valuable tools for researchers of churches and congregations. Photo elicitation and photovoice empower participants, turning them from passive objects of study into emancipated co-creators of research and empowered co-creators of data. We used photo elicitation and photovoice in our separate studies of understandings of communion among young Baptists and understandings of culture among church leaders in Hull. Although our research areas were very different, we found similarities in the way that images can empower participants and in doing so, enable them to be both articulate and dis-articulate, arguing that this dis-articulation is valuable in discussions of belief and experience.
\end{abstract}

\section{Keywords}

photo elicitation - photovoice - culture - communion - participation 


\section{Introduction}

\subsection{Photo Elicitation}

In its simplest state photo elicitation can be described as 'the use of photographs during the interview process,' a method introduced by anthropologist John Collier in 1957 who described 'photo interviewing' and later 'interviewing with photographs' in his research (Lapenta, 2011: 201). Douglas Harper describes photo elicitation as 'the simple idea of inserting a photograph into a research interview' (Harper, 2002: 13). The use of photographs in visual methodology varies hugely depending on the study, as is shown below in section 1.4. Some projects utilise photographs taken by the fieldworker, others encourage participants to take photographs for the purpose of the research, and even these two approaches will be used in differing ways. For example, Eleanor Nesbitt's (1993) ethnographic study of children's participation in acts of worship, part of which explores the subject of children's participation in Holy Communion, used photography. In Nesbitt's study the fieldworker took photographs during acts of worship for participants to reflect and comment on. Researchers may provide photographs that they have taken themselves, or that they have chosen from other sources, and/or participants may bring their own photographs to the interviews and focus groups. There is a variety in approach, but with a unity in the aim of using a visual image as a tool for engagement within the research process. In our paper we describe both interviews where the researcher provided the images to be discussed, and also interviews where the participants took the photographs as part of the project.

\subsection{Photovoice}

A collaborative research method, photovoice was first introduced by Caroline Wang in her 1992 study of Chinese village women (Harper, 2012: 189). Harper discusses how photovoice emerged with a purpose of empowering participants who might normally be 'passive objects in the research process' to effect change or to give voice within a specific context. Wang and Burris drew inspiration from Paulo Freire's 'education for critical consciousness' (Harper, 2012: 19o), and Harper discusses how photovoice is used in different ways and levels of engagement within the fields of sociology in particular.

Within photovoice participants may be encouraged to take photographs of a situation or issue within their community or environment, this can be to address a question or problem as in Wang and Burris' seminal work. Francesco Lapenta cites Rosalind Hurworth's study who describes photovoice as an approach

that asks interviewees to take photographs that they feel portray their daily routines, common events or community life. They subsequent- 
ly talk about the significance and meaning of these images with other members of the community, and the researcher (Lapenta, 2011: 207).

It is an empowering approach in that it encourages a strong engagement of participant with the subject matter. Reflexivity of participant is apparent as they engage with the topic, consider how and what they will photograph, and bring their images and reflections to the interview or focus group discussion. We have drawn on aspects of photovoice within our research as we have sought to empower research participants to take control of the images they will bring to the research conversations, and to seek to hear their voice, or to 'voice their interpretations' (Lapenta, 2011: 207). We note however, the complexity of using such methods and the issue of empowerment as not without contention. As Harper writes,

Determining whether an activity has been empowering may be easier to claim than to prove. Photovoice methods may be easy to use superficially, but they are also a potent method when used well (Harper, 2012: 193).

To address issues of power and empowerment it is important to address ethical issues and to work within best practice. While there is not scope to address this in significant detail here, we outline how we have worked with participants further below. ${ }^{1}$

\subsection{Photo Elicitation and Photovoice in the Study of Religion}

The last ten years have seen an increase in the use of visual research methods in the study of religion. In 2010, Vassenden and Andersson could write that 'the last decades' increase in the visual methods in social science has not been reflected in the study of religion.' They saw a 'perplexing absence' of the use of visual methods, 'given the importance of visual symbolism in many religious traditions' (Vassenden \& Andersson, 2010: 149). In the subsequent ten years visual research methods, including photo elicitation and photovoice have proliferated. Williams and Whitehouse categorise photo elicitation as the most frequently used visual research method in the sociology of religion, measured by the number of publications (Williams \& Whitehouse, 2015: 305). They identify Benetta Jules-Rosette's 1975 ethnographic research on the Apostles of John Maranke as the first to use photo elicitation to study religion (Williams \& Whitehouse, 2015: 310 ). ${ }^{2}$

1 For a fuller introduction to the use of photovoice in a congregational setting see Williams $\mathrm{R}$ (2019) 'Engaging and Researching Congregations Visually: Photovoice in a Mid-Sized Church'. Ecclesial Practices, 6(1), 5-27.

2 For an excellent overview of the use of photo elicitation in the study of religion, see Williams, R \& Whitehouse, K (2015) 'Photo Elicitation and the Visual Sociology of Religion' Review of Religious Research, 57 (2). 
A relatively early use of photo elicitation in the study of religion was Jeffrey Samuels' research among child Buddhist novices in Sri Lanka in 2004. He used autodriven photo elicitation, giving his subjects a camera and asking them to take photographs of their worlds. After giving the participants a list of things he wanted them to take photographs of (including an ideal monk, 'an important temple activity,' 'what makes you happy as a monastic') Samuels simply asked his participants to tell him about the photographs they had taken. He found that the openness of this question was occasionally met with a baffled look, but more often, resulted in 'focussed and detailed descriptions' (Samuels, 2007: 201). Samuels also found that the research process empowered his participants in other ways: for his child Buddhist novices, having a camera and engaging in his research process 'appeared to increase the novices' social standing, especially among their peers' (Samuels, 2007: 201). Samuels found that his participants did not give succinct responses: their conversations were driven by their emotions, likes and dislikes (Samuels, 2007: 215). These responses, however, were detailed, rich and powerful. They led Samuels to re-evaluate his assumptions about the monastic life in Sri Lanka: his participants became the ones leading the direction of Samuel's research, and revealing his limitations (Samuels, 2007: 220).

In wider studies of religion and spirituality, Rosalind Pearmain used images to explore spiritual aspects of self as a basis for qualitative research, with young people aged $15^{-18}$ years, and examined how spiritually moving and stirring experiences may be related to the notion of a direct, participatory embodied attunement to the world (Pearmain, 2007: 75). She created a workshop format where a 'range of pictures was offered from which the instruction was to select any that resonated with them in some way without prior interpretation or analysis... Each young person moved around the room and gathered a range of pictures fairly spontaneously. From these, they could reflect and share what the pictures meant to them' (Pearmain, 2007: 75). Pearmain describes these images as 'evocative cues' which allowed the young people to communicate the 'deeply stirring and moving experiences' of their spirituality (Pearmain, 2007: 76,80 ). She found that the use of images allowed the researcher to

open deeper levels of communication, which are conveyed in image rather than conceptual interpretation (which flattens such communication straight away). It is as if spiritual experience needs a bigger space in which to resonate or be received (Pearmain, 2007: 80).

For Pearmain, using visual research methods mean the researcher and participant enter into this bigger space together as 'a kind of participation project 
for both researcher and subject, who are both held within a field of potential spirituality,' where meaning is 'shared between researcher and participant as a relational and embodied experience, as something known because it is felt' (Pearmain, 2007: 80).

Notermans and Kommers use a variant of photo elicitation in their research into Marian pilgrimage (Notermans \& Kommers, 2013). Their use of iconographic elicitation came about after other methods of data collection failed in research on Dutch Lourdes pilgrims' relationships to Mary, and inserting icons of Mary allowed participants to express themselves fully (Notermans \& Kommers, 2013: 610). They saw photo elicitation as emphasising the active role that participants play in the research process, 'emancipating' the participant into a co-researcher (Notermans \& Kommers, 2013: 622).

Instead of photo elicitation, Sarah Dunlop and Pete Ward used narrated photography in their study of migration and visual culture among Polish Catholic young people (Dunlop \& Ward, 2014). They describe narrated photography as images taken by the participants, accompanied by a narrative generated by the photographer-participant through interviews and focus groups. This differs from the practice of photo elicitation inasmuch as there are no photographs taken by the researcher, which Dunlop and Ward see as containing the risk that the 'participants are puzzled by the images chosen by the researcher and much of the interview time can be taken up with explanations about where an image has come from and what it is' (Dunlop \& Ward, 2014: 32). Dunlop and Ward also note that their narrated photography methods allowed their participants, potentially disempowered young people in a foreign country, to feel empowered: the visual material enabled them to 'place a good deal of power into the hands of the interviewees, because the conversation was centred on the images provided by the interviewees themselves' (Dunlop \& Ward, 2014: 35). It is this sense of empowerment, and the rich data that ensues from it, that we found so valuable about our photo elicitation methods: our participants, whether they were young people or church leaders, were able to assume control in the interview situation by talking about the photographs.

Hendrik de Roest used photo reflection to research the emotions of congregations whose churches were in the process of being closed and explore their bonds of attachment to the building (de Roest, 2013). In photo reflection, participants 'add written and oral comments to their own photographs, as well as select pictures taken by a "third party"' (de Roest, 2013: 301). de Roest found that the photographs evoked 'emotional memories' in the participants, bringing back 'sensory and emotional experience' (de Roest, 2013: 303). He describes photographs as 'vessels, in which people store up meanings, knowledge or experiences': this echoes the way in which we saw our participants unpacked 
the meaning in photographs (both those taken by themselves and by us), and in doing so, shared their emotions and beliefs freely (de Roest, 2013: 301).

Our own use of visual methods drew heavily on photo elicitation and photovoice. Both are collaborative methods and were chosen in our projects to draw out meaning and to give voice to research participants (Harper, 2012, p. 155). Both photo elicitation and photovoice are tools of qualitative methodologies which allow their participants to feel as empowered in the research process as possible and share their beliefs and understandings with the researcher. While we identify the significance of the visual being a significant tool within a creative methodology, we also chose to use visual methods to address issues of power and empowerment.

We were introduced to visual research methods in different ways, but we have found remarkable similarities in the benefits and impact of these methods. Linda's research was an exploration of young people's (13-18-year olds) experience of Communion (Lord's Supper/Eucharist) in their Baptist church contexts. The project sought to understand from young people how they viewed the practice, their own experience, and their understandings - these in relation to faith, being part of the church, and wider views. The findings would speak into Baptist church practice and ecclesiology, with a view to hearing young people's theologies. It was a discovery-based piece of research rather than testing a prior hypothesis. Linda's background in youth work and informal education inspired her approach to the choice of methodology. She wanted to foster good practice in research among young people. As she was accustomed to creating informal learning approaches in church and youth work settings, she discovered connections with visual research approaches and those used by researchers with children and young people and found resonance with methods within the field of visual ethnography. Having a keen interest in photography as an amateur, she was fascinated to bring these areas together in the research process. Hearing Dr Sarah Dunlop present on her photography research project with young Polish migrants on the theme of exploring the sacred $^{3}$ was a catalyst for Linda to shape her research design.

Eleanor was researching theologies of culture emerging from Hull, the UK's City of Culture in 2017. She was working among church leaders from different

3 'From obligation to consumption in two and a half hours: Exploring the sacred with Polish migrants.', at the IASYM Conference, Cambridge 04/o1/12. 
denominations, and, although these people had received ministerial training, she found that many of them had not given particular thought to the concept of culture, or how God might relate to culture. Visual research methods provided an excellent way to uncover her participants' thoughts and beliefs on these topics. Prior to undertaking this research for her PhD, Eleanor was communications officer for the Diocese of York, and as such often photographed events and took pictures for websites, social media and newsletters. Many of her photographs have been printed in local newspapers over the years, but she has had no formal training: everything she learned was from watching press photographers at work, and helping them set up photo opportunities. She discovered the concept of visual research methods on the AHRC-funded Research Methods for the Study of Religion training held by the University of Kent, led by Professor Gordon Lynch.

Linda and Eleanor met and discovered their mutual passion for visual research methods and their research in visual ethnography at the Ecclesiology \& Ethnography Network 2018 conference in Durham, and this paper arises from discussions at that conference.

\section{$3 \quad$ Methods and Results}

\subsection{Method}

In order to enable the empowerment which can be characteristic of photo elicitation and photovoice, and which is noted above by Wang, Harper, Lapenta, Samuel, Pearmain, Dunlop and Ward, we needed to create an environment where our participants felt respected. Issues of confidentiality and consent were addressed prior to the project and guidance on the taking of photographs by participants, given. This was particularly crucial in Linda's work with children: she provided an introduction to the research in her first session, using a PowerPoint presentation and handout to discuss and explain issues of confidentiality and ethics with the young people who were participating. This covered:

1) explaining the purpose of the research

2) where it would take place and over how many sessions

3) an explanation on the use of photographs - both those introduced by the researcher and those to be taken by participants

4) a section on confidentiality and ethics for participant photographs. (For this project a decision was taken to avoid taking identifiable images of people, but if these were included by participants a consent form would need to be completed, and this was provided.) 
5) an explanation of the process for discussing the content of the images, highlighting that conversations would be recorded and used for the purposes of the research, and that participants' names and church details would not be used.

6) considering the benefits and challenges of the project, for example how it could lead to greater awareness of participants' experiences of Communion in their churches but how it additionally may provoke strong feelings and challenges.

7) an explanation of the voluntary nature of participating in the research project and the ability to opt out at any point.

Participants were given a copy of the PowerPoint slides along with a letter of explanation for parents, for both parents and participants to sign. This included seeking permission for use of the participants' images for the purposes of the research.

Drawing on good practice and the approach of the photovoice 4 initiative, Linda used a session to discuss with participants how they might use cameras to take photographs to address the research questions, which she gave to the participants on a postcard at this point. The young people were encouraged to play with the cameras during the session, to have a go at taking photographs as a way of getting used to using them ${ }^{5}$ and to trial the idea of taking photographs to convey meaning. This session introduced the purpose of the study and the methods that would be used. The researcher presented a number of images she had taken to explain and discuss with the participants how photographs of everyday situations, items, and scenes could be used to tell a story and convey meaning, this being the aim of the photography within this project.

Linda worked with 28 young people from 5 different English Baptist churches, working with participants in focus groups over a period of 3 to 4 weeks. She used a mixed-methods approach, with photo elicitation as a key element and photovoice as an influence and inspiration. In the first session she used images that she had either taken herself or collated from elsewhere to engender discussion with the participants about what Communion was. The images were chosen to open up conversation on the topic of Communion and included a mix of traditional elements of bread and wine set up for

4 https://photovoice.org/.

5 A number of simple point and shoot cameras were provided for the participants to use if they would like to. This was to overcome any assumption that all young people have camera phones that they can use. While most of the participants used their own phones or cameras for the project, a small number borrowed cameras from the researcher. Additionally, having a number of cameras to use in the introductory session enabled participants to get used to the idea of using a camera and taking photographs. 
Communion, a Communion table/altar, a cross, a crucifix, and more everyday images of grapes and supermarket bread, sandwiches, a family sharing a meal. Each of these images the researcher identified as having content that could be connected in some way to the theme of Communion or additionally could be an image to provoke thought, all to assist in enabling reflection and to open up conversation. For example, an image was included of bottles of Coca Cola (which had names on the bottles), an image of cartons of 'Ribena,' both images of ordinary drinks, one with an additional grouping of names. How would participants consider the content of these images in relation to how Communion is practiced in their church, would they help them to relate to this aspect of worship? Given that most Baptist churches use a non-alcoholic alternative for wine in Communion, these images were deemed potentially useful for encouraging the participants to consider and critique the practices in their own churches.

Linda used the photographs in a number of ways with the focus group discussion. Initially, she asked the participants to choose one or more image that resonated with the participants about Communion, and one or more that they felt had no connection for them with Communion. She used the image of a person being baptised to ask if participants felt there was any relevance to this (Baptism) and Communion, and the image of Piasecki's Lord's supper to consider their Biblical understanding of Communion and who might have been present. This led to conversations about inclusion and in particular the presence of children.

In the first session Linda presented a photovoice element, introducing a task of the project for participants to take photographs themselves to address the statements: 'Communion - what it is to you - how you feel about how it's done if you could re-imagine it....' A good number of the participants stayed with the project for all of the sessions with 19 out of the original 28 going on to produce their own images. Just 4 of these produced a collage of images taken from elsewhere (generally internet sourced but collated into their unique picture). In total there were 62 photographs produced by participants as part of the project. Additionally, the groups were asked whether they would like to present their images back to their own church at the end of the project. Three out of five of the groups did this, resulting in their individual images being collated by them (as a group task) into large collages to which they added wording chosen from the elicitation process and those they additionally chose to include. This provided a further 3 visual elements of data to the project.

Eleanor used photo elicitation interviews to research theologies of culture arising in Hull, the UK's City of Culture in 2017. Eleanor interviewed 20 church leaders of different denominations twice: once before City of Culture 2017, and 
once afterwards. For the pre-City of Culture interviews, she provided photographs to elicit comments and discussion in the course of a semi-structured interview. Eleanor had taken the majority of these photographs herself, and focussed on subjects which would enable her participants to reflect on the concepts of religion and culture, and the relationships between religion and culture, and God and culture. She included what might represent traditional, or 'high' forms of culture, some of Hull's historical fishing industry, images from Hull's more deprived estates, and images which might represent 'low' or less formal forms of culture: street art on a telephone exchange box, The Duke of Edinburgh pub, and the ксом Stadium. She also provided ambiguous images: flowering plants behind a fence, crowds of people, and a sculpture of a fish. In these first interviews, Eleanor asked her participants if they would be willing to take photographs during 2017 that said something to them about God and culture. She reminded them about this at several points during 2017. Of her original 20 participants, 16 were interviewed again in January and February 2018.

\subsection{Results}

In Linda's research, photo elicitation with the images taken by the researcher opened up reflection in a deep way and one which Linda anticipates would not have been so rich had sessions been purely question or questionnaire based. She observed how the use of photo elicitation with the researcher-provided images enabled an easy flow of discussion in the focus groups, allowing for comment, for agreement or disagreement, some drew strong responses. A benefit of using the visual with young people in this way is there is no 'over-reliance on words' young people are better able to articulate themselves and in less intimidating ways (Heath et al, 2009: 125-127). While the responses from participants were not always clearly articulated there was interesting and insightful discussion with participants exploring meaning and expressing often complex thoughts which often arose out of one participant's reflection on their chosen image which was taken further in the focus group discussion. This met the aim of the methodology to use the medium of images to enable the participants to give voice to concepts which may well be difficult to verbalise. Taken on their own, the participants' reflections on the images provided by the researcher would have had less to say, but within the focus group they elicited a breadth of response as conversation and discussion flowed.

For example, a participant chose the image of a row of 'Coca Cola' bottles each with personal names on their labels as resonating with them in relation to Communion, expressing how it made them think about how 'God shares bread and wine with us, we share coke, and coke is special.' These themes 
were picked up by the group, some discussing why 'coke' could be special and relevant and another participant reflecting on the personalised nature of the bottles, 'It's like God shares with people individually as a person per person, so I agree with like the sharing thing for the fact of that...' Further discussion followed with the addition of another person's chosen image of cartons of a blackcurrent soft drink, 'Ribena'.

The participant suggested it was 'very this churchy...because we don't use wine,' reflecting on the similarity with the drink that is used for Communion at their church being non-alcoholic. Other participants discussed the symbolic element of the Communion 'drink' and questioned what would be appropriate if it could be something different.

These responses reveal an engagement with the subject, from the everyday view of the images as normal drinks to them representing the blood of Jesus. Participants were able to reflect on the practices within their own churches, from discussing the elements used for Communion in their setting, to re-imagining what other drinks or simple meals could be representative of a Communion meal. In one church group the young people commented on how they were part of the team who prepared the elements for Communion, which touched on the community aspect of their involvement in church life, and their sharing of responsibilities alongside adults. What the photo elicitation aspect of the focus group session enabled was an opening up of conversation on the theme of Communion, and in the participants settings. It enabled young people's voices to be heard on their views, their experiences and understandings, and allowing their personal and group reflections on the practices in their churches.

The participant produced images provided another level of participation in the project. Each of the participants shared their photographs with the researcher and were encouraged to express what was represented within the image through a process of photo elicitation. The results were many and varied. Data was gathered by transcribing the focus group discussions and the individual photo elicitation interviews with the young people. The data was placed by theme into a grid and narratives emerged of themes from the young people of their experiences and theologies. Additionally, the participant photographs were collated and categorised into type and theme, further analysis of the participant images alongside the words spoken with them was made. The researcher noted how images were presented in different ways, how some were specifically staged, others were produced on the spur of the moment but reflected on with detail. Others of normal day to day objects provided a tool for reflection. Some participants chose to create a collage of images from other sources. A number of similar types of photograph had been presented, for 


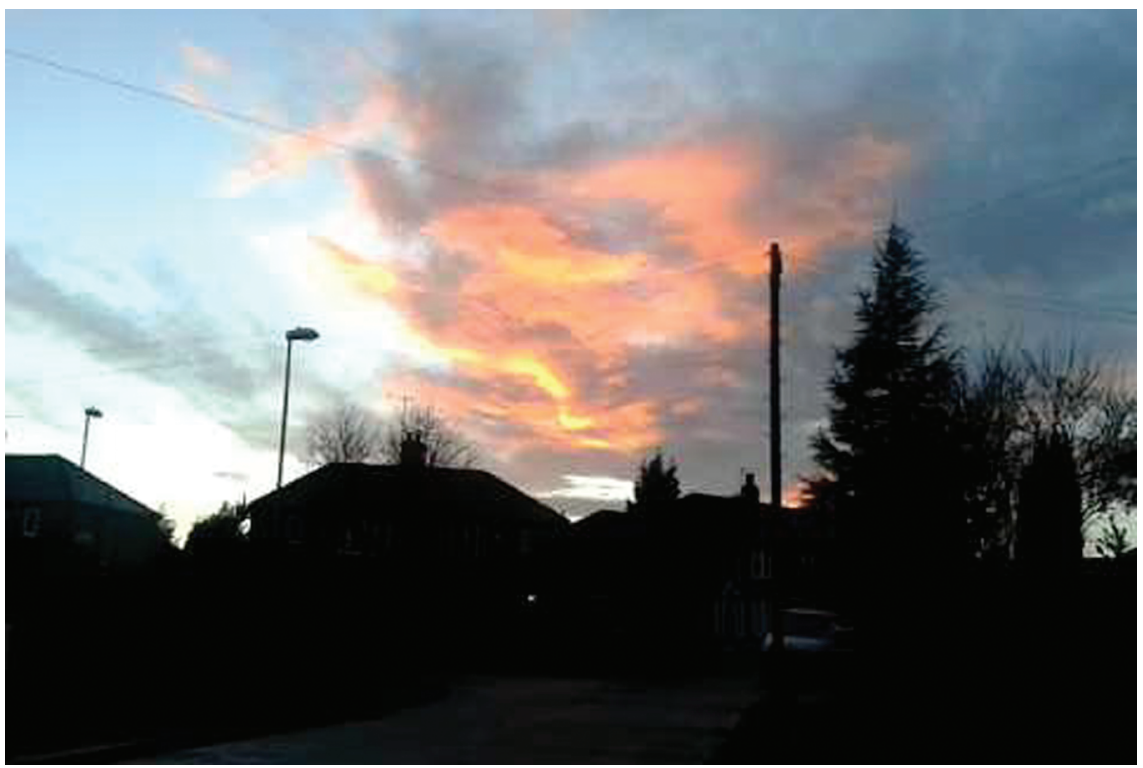

IMAGE 1 Sunset

PHOTOGRAPH: LINDA HOPKINS, 2015

example, Image 1 of a sunset was one of a number of sunsets or themes from nature. This participant used her image to talk about the relationship she felt with the experience of Communion and with God:

in my mind it's like the sky is a connection with God, so it's what I think... Communion is about connection and the silhouettes are kind of like the dark things in life that you erm, times like greed and like times when you don't think about your faith and stuff...

It was with photographs of the natural world that many reflections were made on the nature of God, and of the relationship with God that the participants felt. This fits with a 'turn' within visual ethnography towards acknowledging and studying the 'senses,' that use of visual research 'offers a route to comprehending those aspects of experience that are very often sensory, unspoken, tacit and invisible' (Pink, 2013: 47).

Images were used to express understanding, spirituality and theology, others to suggest change, or simply to make connections. In Image 2 the participant explained how they felt Communion could be experienced in a better way - as a meal around a table rather than for individuals sat in pews. The participant presented a number of staged images, this one showing a group of teddies sitting around a table, each with a piece of bread, a candle at the centre 


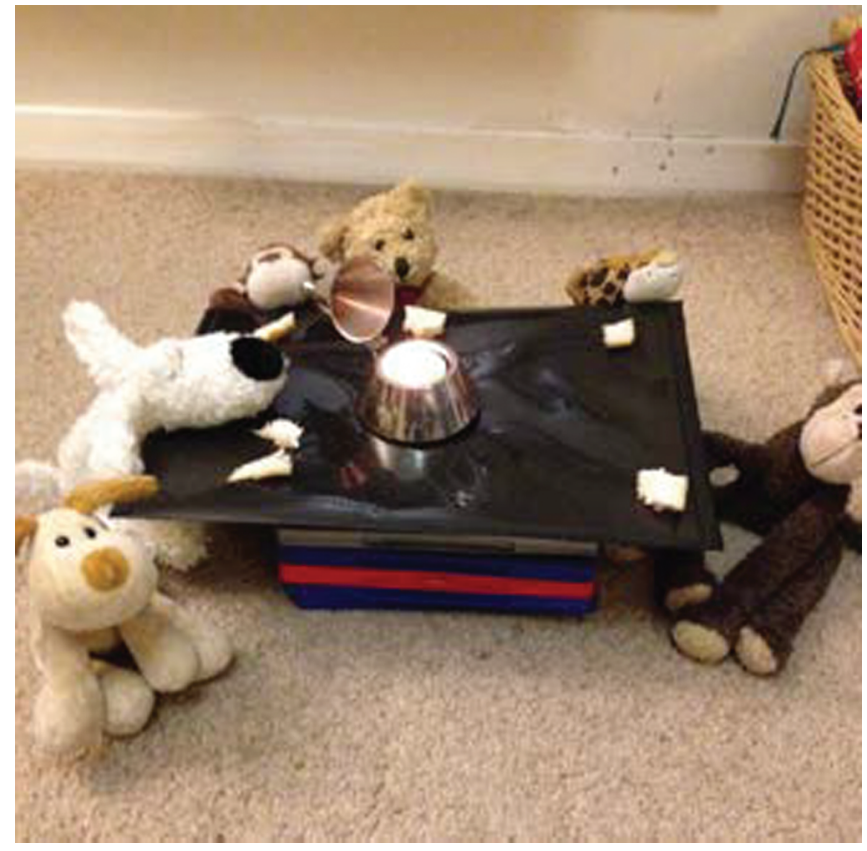

IMAGE 2

Communion Meal PHOTOGRAPH: LINDA HOPKINS, 2015

of the table. The participant makes a connection between the last supper, as a meal, and how it would be better to 'do it [Communion] more of a meal and be able to talk together' through his curated image.

The researcher gained insight into the experience of Communion for the young person, their reflexivity and Biblical reflection, and their consideration for how it could be different.

Many of the participants made connections with everyday objects and the Communion meal and experience. One participant, with Image 3, saying, 'Mine are basically on the theme of sharing, cos like this image, the bread rolls later on in the day they were taken to a birthday party by Dad.' Adding, 'I just saw bread and Vimto and thought, bread and Vimto - bread and wine kind of thing.' Adding, 'It's like what we do at home is like a mini Communion type thing.'

There were different levels of expression through such images. The participant was making a connection with the everyday and the ordinariness of the bread and wine, and a theme that came through many of the participants' images of the importance of Communion as sharing was expressed. Doing Communion together with a community of others was identified as important, as was the personal, individual element to it. Many of the participants talked of connection: them with God, them with others, the elements of Communion with ordinary bread, wine, coke, crisps, cake. The images and process of photo 


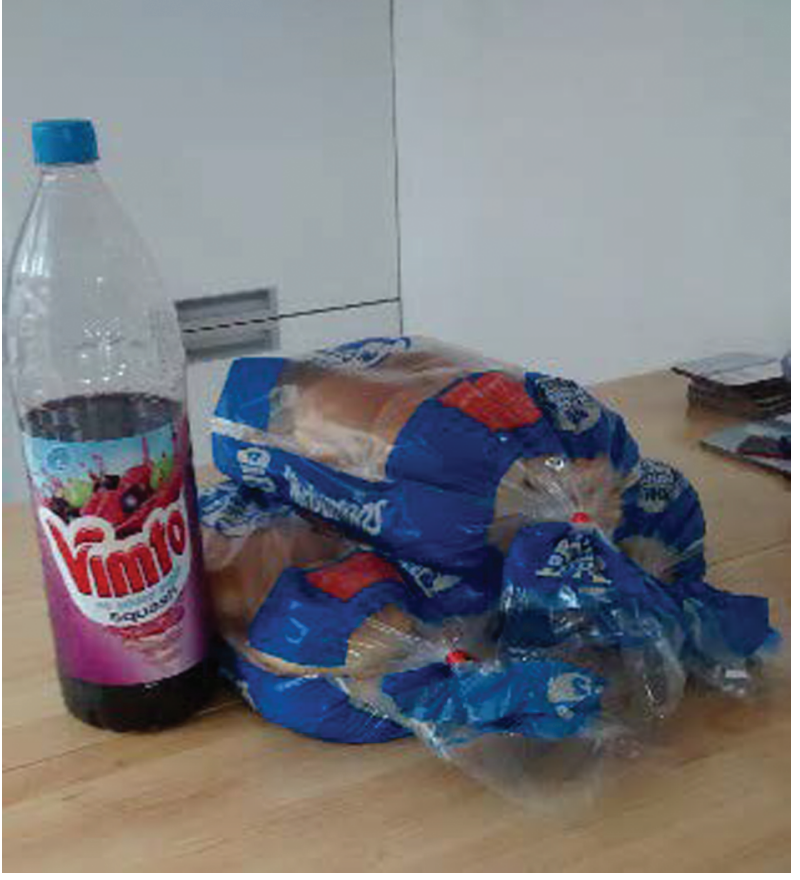

IMAGE 3

Bread rolls and Vimto PHOTOGRAPH:

LINDA HOPKINS, 2015

elicitation provided rich data for the research as the participants made meaning of Communion, made connections with the material elements of the ritual and their self-understanding, as well as expressing concern for others which additionally came through strongly in the project.

Similar to Linda's experience, Eleanor's photo elicitation interviews yielded rich and deep data which Eleanor does not believe would have been gained by verbal interviews alone. Her participants used the photographs from the first interviews to explain that they thought God was positive about human culture. Participant 8 (Anglican) spoke about a picture of street art on a telephone exchange box (image 4), saying:

I think when it comes to God and culture, God is wild and God is colourful and diverse and I think that's how He made us and I think culture for God is about life, enjoying, peace and love and culture is good. I think that sort of, it's a bit random. It doesn't really make much sense, but it doesn't have to. It's colourful. 


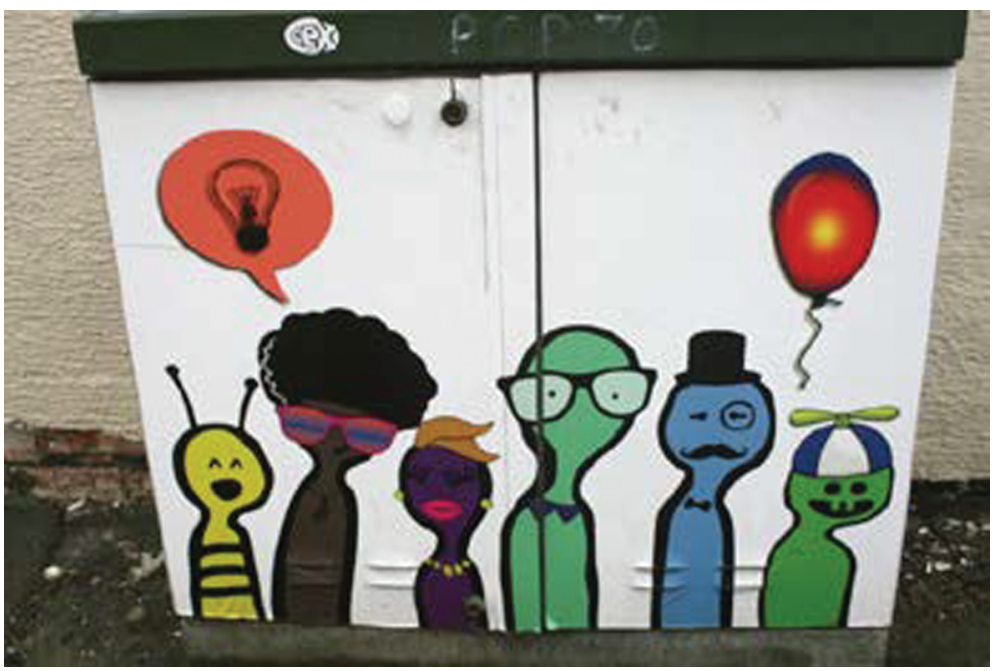

IMAGE 4 Street art on a telephone exchange box PHOTOGRAPH: ELEANOR WORT, 2016

Many participants believed that God wants people to flourish, and that culture is a way that people can do so. Participant 10 (Quaker) chose a picture of flowering plants behind a fence (image 5), saying 'The flowers in that picture are representing the flourishing and that sense of being who we are - and a healthy culture is a culture where things are flourishing and being what they are.'

In the second interviews, Eleanor's participants showed her the photographs they had taken.

Participant 12 (independent Evangelical) discovered a sense of joy in the City of Culture events which he felt God wanted for the city. He kept calling City of Culture 'crazy' and 'bizarre,' so Eleanor asked him to expand on this. Talking about the selfie below (image 6), which he had taken, he said:

Fun... I want people of Hull to be fun and I want the church to be fun. So, that's why in the front window, I put a big poster for Yellow Day. I bought a banana, anything I could buy yellow in the pound shop. People would come past, "Oh, what's this about?" The people from the church said, "What is it?" I said, "It's just fun". There's no rhyme or reason, it's not evangelistic, it's not a Christian thing, it's just Yellow Day, that a comedian, comical guy has come up with. 


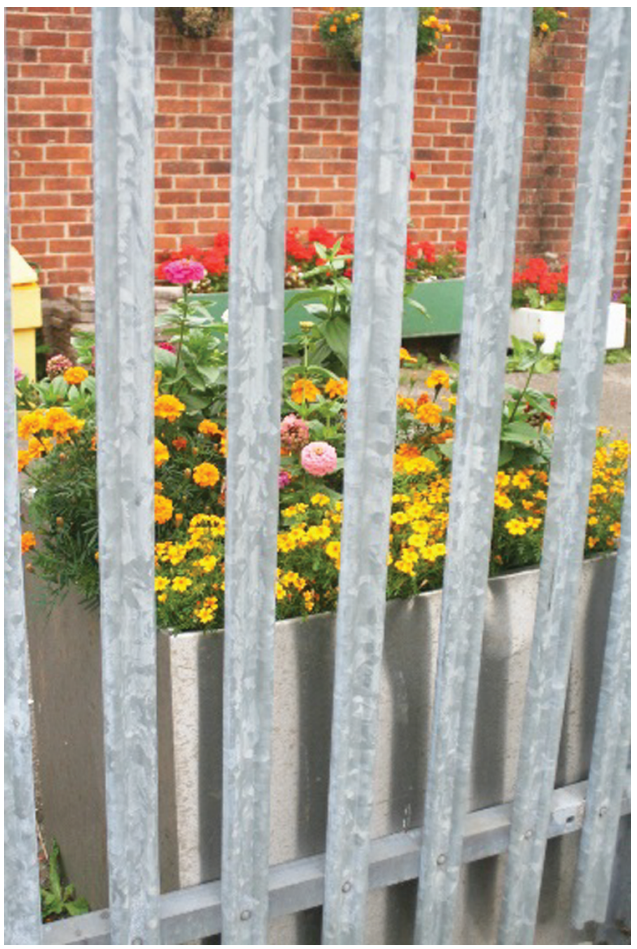

IMAGE 5

Picture of flowering plants behind a fence

PHOTOGRAPH: ELEANOR WORT, 2016

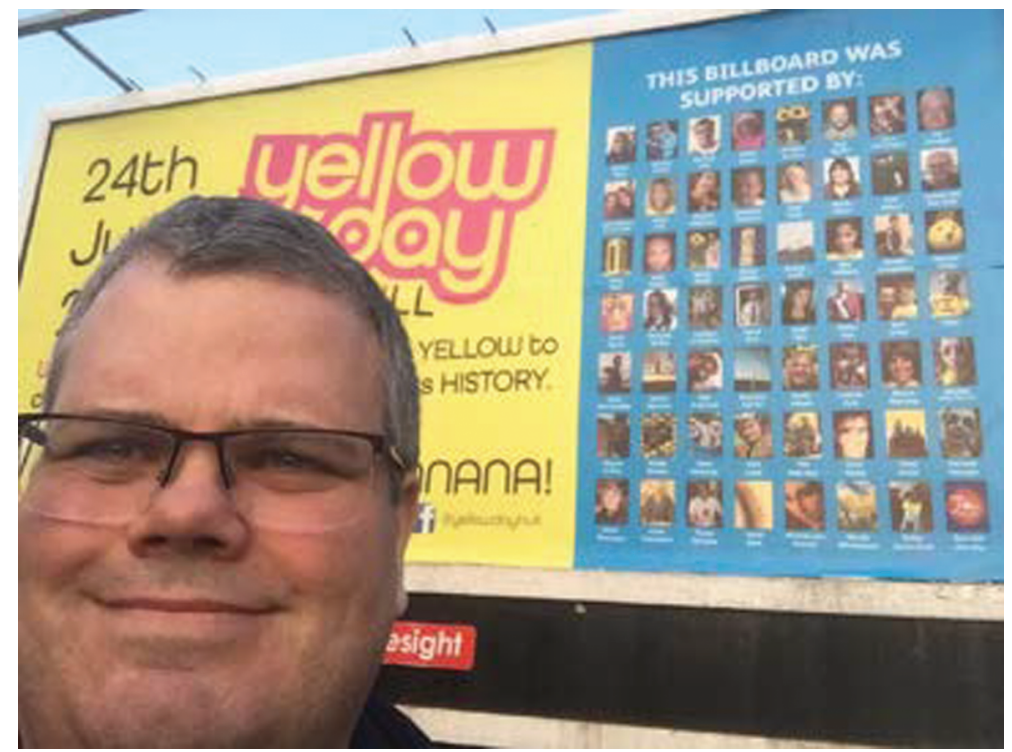

IMAGE 6 Yellow Day selfie

PHOTOGRAPH: STEVE WHITTINGTON, 2017 


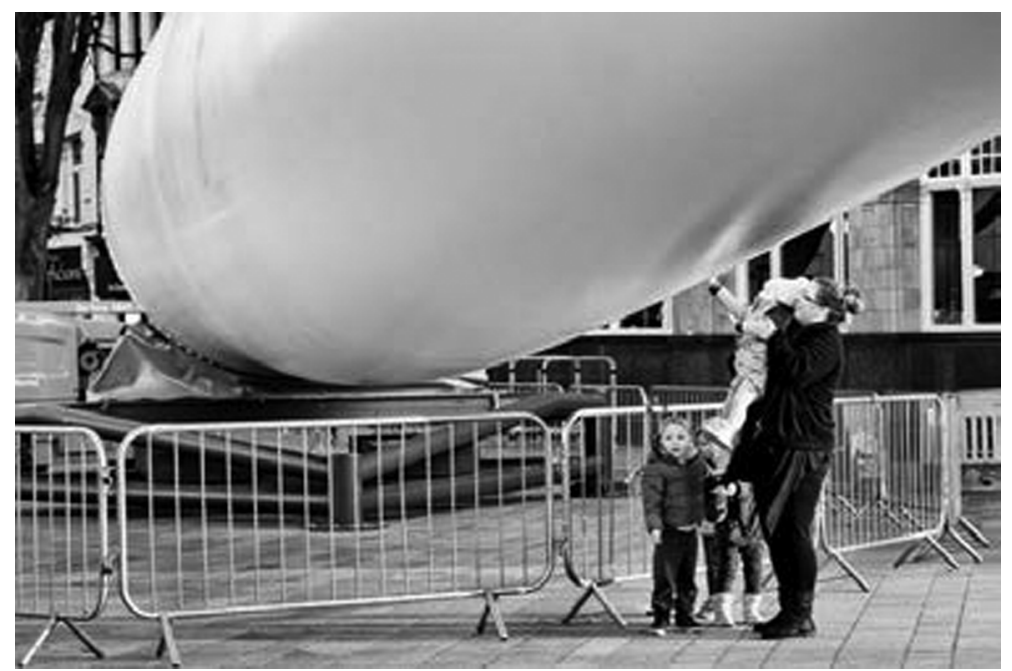

IMAGE 7 The Blade

PHOTOGRAPH: DAVID PERRY, 2017

Eleanor got the sense it was unusual for him to endorse something that was not Christian or evangelistic, but he clearly felt God wanted the people of Hull to have fun and be joyful, for the sake of having fun and being joyful. He trusted her with this insight, that it was ok to just have fun, without utilising this sense of fun for evangelism, and that God wanted people to have fun for its own sake.

Eleanor's participants also used their photos to express deep theological beliefs. Participant 4 (Methodist) had taken pictures of the Blade, a 75-metre turbine blade installed in Queen Victoria Square (image 7). He described it as

It's so out-of-place that it's beyond belief! And to me, you know, that's exactly how God is, you know, sort of, here's God in the middle of the city and it's like that does... it just... just does not fit! It does not compute! And what sense can we make...? So, I wanted to convey something that made sense... This seemed way too sort of the world of prophet evangelists... you know, what on earth can you say about something so extraordinary? How do you bring it back down to earth for ordinary people again so, this is where we are in the church, you know, trying to do that for people? Yes, then this one - it was the juxtaposition of the extraordinary, the outlandish, the out of the ordinary against the traditional and framing the traditional through the... extraordinary! And again, this is what we do, whether its apologetics or if its mission, whatever we're doing. 


\subsection{Empowering Participants}

In our different areas of research, we both found that using photo elicitation and photovoice empower participants, 'emancipating' the participant into a co-researcher (Notermans \& Kommers, 2013: 622). We discovered this empowerment and emancipation in both the sessions with researcher-generated and participant generated photographs. Although Dunlop and Ward identify that researcher produced photographs contain the risk that the 'participants are puzzled by the images chosen by the researcher and much of the interview time can be taken up with explanations about where an image has come from and what it is' (Dunlop \& Ward, 2014: 32), we did not find in practice that this was the case. Instead, our participants read ideas or symbols into our photographs which we had not seen, allowing our participants to 'own' the process and express their own thoughts.

Eleanor found this to be the case with image 8, a picture of a Mosque in Hull, which she had provided as an example of other religious cultures in the city. However, those participants who picked the image did not recognise it as a Mosque, and used the fence around the building, in conjunction with

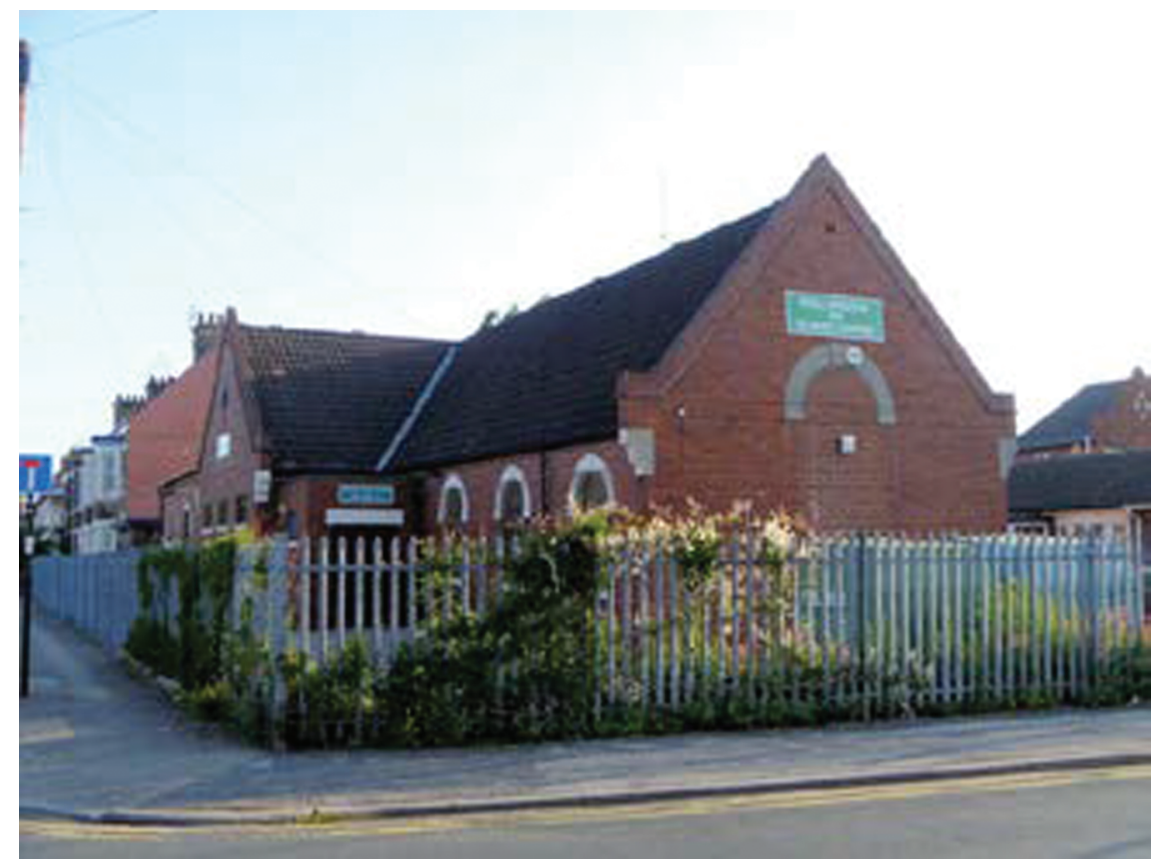

IMAge 8 Hull Mosque

PHOTOGRAPH: ELEANOR WORT, 2016 
Image 7 (flowering plants behind a fence, shown above) to talk about things which stopped people from flourishing. Her aims in providing the picture were co-opted by her participants, as they "took control" of the image to use it for other purposes.

Eleanor also found that her participants became empowered by bringing concepts to her research she had not considered, and thus becoming true co-researchers. Participant 9 (Anglican) was an example of this, bringing the concept of reconciliation to Eleanor's attention. Participant 9 's church had held services and events to mark the role of fishing in Hull's history as part of the City of Culture. He showed Eleanor a picture of the Bishop of Hull, the Rt Revd Alison White, and a plaque marking the 5oth anniversary of the triple trawler disaster, which was blessed at the 2017 Sea Sunday service (image 9).

Talking about the picture, he started talking about reconciliation between two previously antagonist fishing heritage groups:

It's a bit like the People's Front of Judea and the Judean's People Front. But, because of my role, I'm a local lad who worked in the fishing industry, it's a great opportunity for me to work with both groups and to bring them together... we're doing a lot more than just remembering, we're actually reconciling.

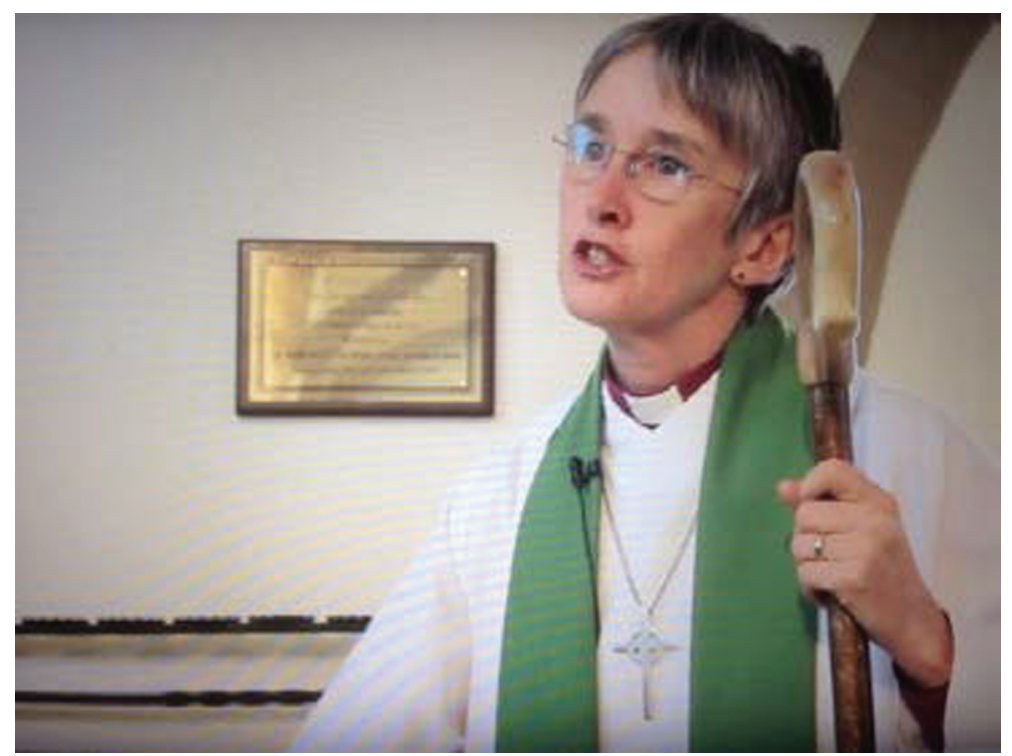

IMAGE 9 Bishop of Hull

PHOTOGRAPH: TONY COTSON, 2017 
He felt his church, in its role as the 'Fishermen's church,' allowed these groups to come together, and God to bring some reconciliation:

I think the reconciliation aspect was something that slowly, those opportunities became clearer. Sometimes it's not until you're actually engaged in the process that you can see, this is not actual by product of what we're doing, this is God at work here. Because, such were the divisions between these opposing groups, the Spirit had to be at work with what's going on there. But you can actually begin to see something is happening. It's at a much deeper level than you could have ever hoped and then you can begin to actually fan the flames of that to make it happen. Then to see the possibilities, the opportunities that lie in the future.

Without her participant's photograph, Eleanor would not have understood that reconciliation was a crucial element for the churches in Hull, City of Culture 2017. This picture, which could be seen as just a Bishop and a plaque, became a vehicle whereby her participant led the research process and changed her frames of reference about God and culture in Hull 2017.

Linda found a similar sense of empowerment in her research, as her participants played with images of food and drink to explore the ideas of Communion and presented images they had taken from everyday life, the natural world, collated pictures and curated scenes. Through their images the young people were able to express their experiences and to make connections with the Communion meal, church life, and their relationship with God.

Allowing her young people to take photographs of their own ideas of Communion encouraged the young people to enter into a process of discovery and to name their own meaning. Greene and Hogan suggest understanding experience involves 'interpretation,' and in this case the young people and researcher are in a process of interpreting meaning and understanding together (Greene \& Hogan 2005: 5). Through the process of photo elicitation, a conversation the participants have with the researcher and their peer group (focus group) about their images, these interpretations are verbalised and the participants are given voice. In defining 'voice' Hadfield and Haw suggest it 'privileges experience,' and 'relies on an interior authenticity' arising out of the complex process of articulating and communicating personal meaning to others:

Voice is meaning that resides in the individual and enables that individual to participate in a community ... The struggle for voice begins when a person attempts to communicate meaning to someone else. Finding the word, speaking for oneself and feeling heard by others is all a part of this 
process ... Voice suggests relationships: the individual's relationship to the meaning of her/his experience and hence, to language, and the individual's relationship to the other, since understanding is a social process (Hadfield \& Haw, 2001: 485-502).

By enabling the participant voice to be respected and drawn out, photo elicitation and photovoice can overcome issues of power in the research process. We argue that the use of photo elicitation and photovoice provided a freer environment and context for our participants to communicate authentically and to overcome any 'pedagogic voice' from the researcher (Thomson, 2008).

\subsection{Allowing Articulation and Disarticulation}

As we discovered that photo elicitation and photovoice empowered our participants, we found it gave them confidence to be both articulate and dis-articulate. In their study of migration and visual culture among Polish Catholic young people, Dunlop and Ward found that one of the great strengths of using the visual to portray religious concepts is that 'it gives a person the means to express the inexpressible, and that visual methods bypass cognitive thought processes to engage with the emotive, reactive, subconscious ways that people live out religion... thus mediating the subjective' (Dunlop \& Ward, 2014: 46). We found that as our participants talked about our images and theirs, they were both hugely articulate and also dis-articulate when expressing the inexpressible.

One example of the tension between articulation and dis-articulation, from Linda's research was image 10, from a thirteen-year-old young person.

The participant expressed his dis-ease with the practice of Communion in his church through the blurred image of his pet rat which moved as he took the photograph. He explained,

'I took it [the photograph] and then I thought of something... And I thought, that sometimes it can be a bit intimidating when they're passing the bread and stuff round and expecting you to take it and you don't feel comfortable.' This participant could not fully express his feelings of discomfort around Communion in a simple or articulate way, and needed to mediate this conversation with the image of a pet rat: a dis-articulate image to allow a dis-articulate conversation, but one that nevertheless expressed great meaning.

Similarly, in Eleanor's research, participant 4 (Methodist) used his image of the Blade (image 9 (above)), to try and describe the un-describable nature of God, saying 'it's so out-of-place that it's beyond belief! And to me, you know, 


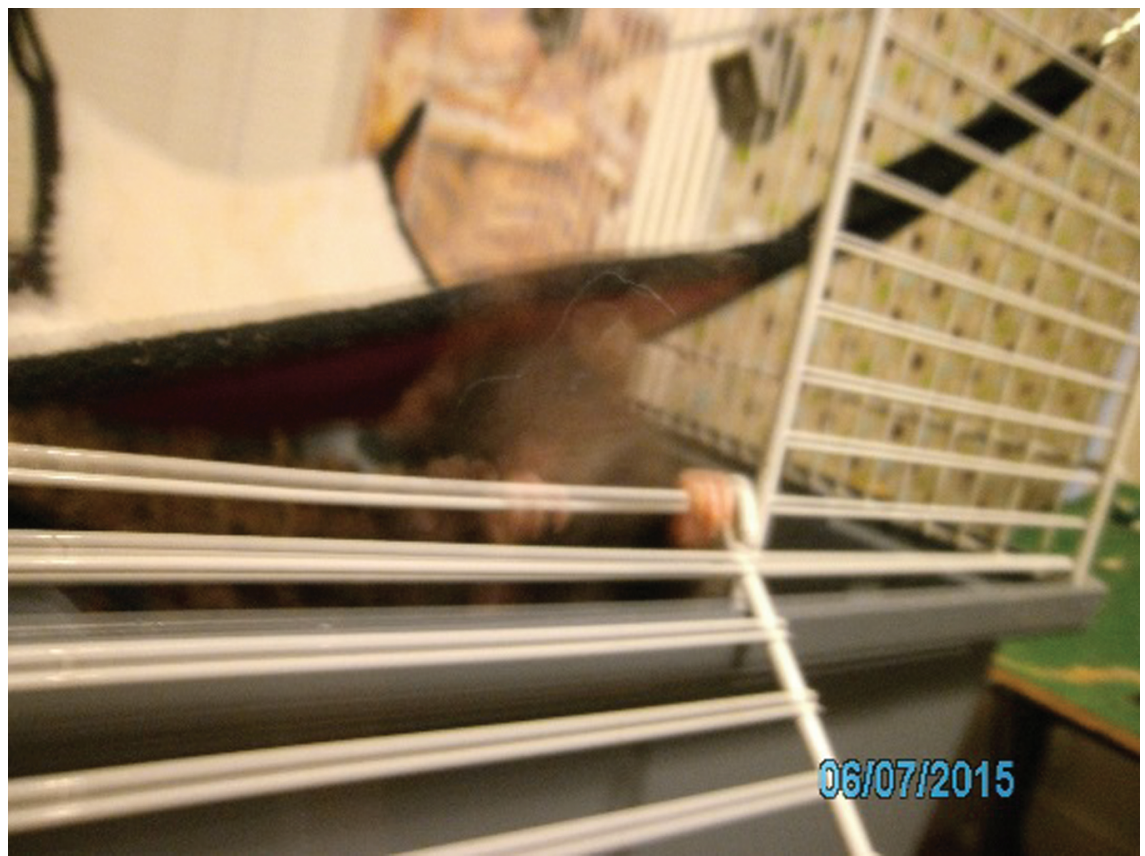

IMAGE 10 Pet Rat

PHOTOGRAPH: LINDA HOPKINS, 2015

that's exactly how God is, you know, sort of, here's God in the middle of the city and it's like that does... it just... just does not fit! It does not compute!.' This is a well composed, articulate image, and sharing it allowed this participant to be inarticulate about God.

We have explored above how photo elicitation and photovoice empower participants, turning them from passive objects of study into emancipated co-creators of research. In being so empowered, we found that our participants' voices, and both their articulation and dis-articulation about sacred matters could be heard: that which is 'known through feeling, image, and sensation rather than words' (Pearmain, 2007: 80-1). The use of images described above often resulted in fragments of thought, glimpses of belief, and half-shaped experiences. We saw this in our participants halting descriptions of the nature of joy, the sense of dis-ease with existing Communion rituals, and the essence of God in today's world. 
Using visual research methods means the researcher must be comfortable with this dis-articulateness, with ambiguity. If, per Dunlop and Richter, images do operate at a 'subconscious, intuitive level' (Dunlop and Richter, 2010: 209), we cannot expect the responses generated by images to be able to be fully articulated in words. But it is exactly this dis-articulation, with its glimpses of awe and wonder, that is the strength of visual research methods. These methods do not provide obvious, safe answers: they will surprise both participant and researcher. The skill of the theological researcher is then to catch the vision of the participant, to piece together the insights and dis-articulation, and to weave them together to form a bigger, clearer picture.

\section{References}

Dunlop, S. \& Ward, P. (2014) 'Narrated Photography: Visual Representations of the Sacred Among young Polish migrants in England'. Fieldwork in Religion 9 (1).

Dunlop, S. \& Richter, P (2010) 'Visual Methods' in Collins-Mayo, S \& Pink, D. (eds) Religion and Youth. Abingdon: Routledge.

Greene, D. \& Hogan, D. (2005) Researching Children's Experience: Approaches and Methods. London: Sage Publications Ltd.

Hadfield, M. \& Haw, K. (2001) “'Voice”, Young People and Action Research'. Educational Action Research 9 (3).

Harper, D. (2002) Talking about pictures: A case for photo elicitation. Visual Studies, $17(1)$.

Harper, D. (2012) Visual Sociology. Abingdon: Routledge.

Heath, S, Brooks, R, Cleaver, E, \& Ireland E (2009) Researching Young People's Lives. London: Sage.

Lapenta, F. (2011) 'Some Theoretical and Methodological Views on Photo-Elicitation' in Margolis, E. \& Pauwels L (eds.), The Sage Handbook of Visual Research Methods. London: Sage.

Nesbitt, E. (1993) 'Photographing worship: Ethnographic study of children's participation in acts of worship' Visual Anthropology, 5 (3-4).

Notermans, C., \& Kommers, H. (2013) Researching religion: the iconographic elicitation method. Qualitative Research, 13 (5).

Pearmain, R. (2007) 'Evocative Cues and Presence: Relational Consciousness within Quantitative Research' International Journal of Children's Spirituality 12 (1).

Pink, S. (2013) Doing Visual Ethnography, Third Edition: Images, Media and Representation in Research. London: Sage.

de Roest, H (2013) 'Losing a Common Space to Connect': An Inquiry into Inside Perspectives on Church Closure Using Visual Methods" curs. 
Samuels, J. (2007) 'When Words Are Not Enough: Eliciting Children's Experiences of Buddhist Monastic Life Through Photographs'. in Stanczak, G (eds) Visual Research Methods: Image, Society, and Representation. Thousand Oaks, Calif: Sage.

Thomson, P. (2008) Doing Visual Research with Children and Young People. London: Routledge.

Vassenden, A \& Andersson, M (2010) 'When an image becomes sacred: photoelicitation with images of holy books' Visual Studies, 25 (2).

Williams, R. (2019) 'Engaging and Researching Congregations Visually: Photovoice in a Mid-Sized Church' Ecclesial Practices, 6(1).

Williams, R \& Whitehouse, K (2015) 'Photo Elicitation and the Visual Sociology of Religion' Review of Religious Research, 57 (2). 